\title{
SOBRE EL ARISTOTELISMO DE ALFONSO DE CARTAGENA. EN EL DEBATE JURÍDICO Y ECLESIOLÓGICO*
}

\author{
Luis Fernández Gallardo \\ $U N E D$ \\ 1feg0003@yahoo.es
}

La aportación de Alfonso de Cartagena, el célebre prelado converso del linaje de los Santa María de Burgos, a la tradición aristotélica no fue de menor trascendencia que la que hizo en otros ámbitos de la cultura y las letras castellanas del siglo Xv. Es más, cabe considerarla decisiva, por cuanto determinó uno de los episodios más destacados en el desarrollo del humanismo castellano, la denominada Controversia Alphonsiana, así como la proyección exterior de su obra, que caracterizara Marichal en un ensayo ya clásico como un «afán por salir de monólogo y de las interrogaciones provincianas, por establecer vínculos con los humanistas transpirenaicos» ${ }^{\perp}$.

\section{Aristotelismo anterior a la experiencia basiliense}

En la rica personalidad intelectual de Cartagena el aristotelismo constituye una faceta central. Aun cuando en sus años de estudiante en Salamanca no cursara oficialmente Filosofía moral, dado que no se requería grado previo en Artes para ser bachiller en Leyes o en Cánones ${ }^{2}$, dicho aristotelismo hubo de ser deudor del que se cultivaba en la universidad salmantina, que había de

\footnotetext{
* Este trabajo se inscribe en el marco del proyecto de investigación Alfonso de Cartagena. Obras Completas FFI 2014-55902-P y FFI 2017-84858-P (MINECO y MICINN, Gobierno de España).

${ }^{1}$ Juan Marichal, «El proceso articulador del siglo xv: de Cartagena a Pulgar», en Teoría e historia del ensayismo hispánico, Madrid, Alianza Editorial, 1984, p. 22.

${ }^{2}$ Según establecen las constituciones de Martín V (1422), que, en este punto, seguiría la práctica contemplada en las anteriores de 1411 y 1381, ambas debidas a Pedro de Luna (papa Benedicto XIII) (Luis Fernández Gallardo, Alonso de Cartagena (1385-1456). Una biografia politica en la Castilla del siglo XV, Valladolid, Junta de Castilla y León, 2002, pp. 60-63).
} 
estar determinado por la exégesis de Santo Tomás ${ }^{3}$. De su arraigo ofrece un elocuente testimonio el ilustre canonista, coetáneo de don Alfonso, Juan Alfonso de Benavente, quien, según el testimonio de Marineo Sículo, escribió sendos comentarios de la Retórica y de la Ética de Aristóteles, hoy perdidos ${ }^{4}$.

En torno a la lectura e interpretación de la Ética Nicomáquea se desarrollaron episodios destacados de la abundante y variada obra literaria y publicística de Cartagena. Su primera obra original, el Memoriale virtutum (c. 1425), es precisamente una exposición de la doctrina ética aristotélica. Las circunstancias en que se gestó ponen de manifiesto su decidido aristotelismo ${ }^{5}$ : el Memoriale no sería sino la reelaboración sistemática de la docta exposición sobre las virtudes que desarrolló el entonces embajador castellano en la corte lusa ante el príncipe don Dionís.

Al plantearse una exposición sobre los fundamentos de la moral, Cartagena, consciente de que la literatura sobre «philosophia moralis» es no solo extensísima, sino inabarcable, afirma, no obstante, que toda ella se halla contenida en los cinco libros de Aristóteles en que se desarrolla la doctrina relativa a la dirección de las costumbres del hombre:

OMNIS DOCTRINA, que ad dirige(n)dos mores hominu(m) traditur, in tria genera principaliter diuidi solet. Primum est eo(rum) q(ue) tangunt ad regimen proprie persone. Secundum est quod pertinet ad regimen domus. Tercium est quod tractat de regimine ciuitatis [...] Primum regimen, quod est $\mathrm{p}(\mathrm{ro})$ prie persone, tractat Philosophus in libro Ethico(rum), quem distinxit per dece(m) libros. Et quia tunc regitur bene homo quando vtitur virtutibus $\tau$ ad vsum uirtutum deseruiunt bona exteriora, nam inter uirtutes sunt alique que sine $\mathrm{p}($ ro) speritate exerceri no(n) possunt, ut magnificencia, cuius exercicium requirit maximos sumptus, quos quis habere non posset sine maxi(m)a habundancia rerum temporalium. Et quia hanc prosperitatem vocant homines bonam fortuna(m), jdeo Philosophus composuit quemdam libellum breuissimu(m) de bona fortuna. De secundo regimine quod est domus, co(m)posuit que $(\mathrm{m})$ $\mathrm{da}(\mathrm{m})$ librum, qui dicitur Ychonomicha $[\ldots]$ De tercio regimine quod est

${ }^{3}$ Las constituciones benedictinas (1411) establecían en la regulación del sistema de pecia que habrían de adquirirse las exposiciones de Santo Tomás y Gil de Roma «super utraque philosophia» (Vicente Beltrán de Heredia, Bulario de la Universidad de Salamanca (1219-1549), Salamanca, Universidad de Salamanca, 1966, t. II, p. 26). Ofrece una espléndida perspectiva de la recepción y estudio de la Ética de Aristóteles en las universidades europeas del Medievo David A. Lines, «Moral Philosophy in the Universities of Medieval and Rensaissance Europe», en History of Universities, 20:1 (2005), pp. 38-80 (para el ámbito salmantino, pp. 49-52).

${ }^{4}$ Bernardo Alonso Rodríguez, Juan Alfonso de Benavente, canonista salmantino del siglo XV, RomaMadrid, CSIC, 1964, pp. 43-44.

${ }^{5}$ Luis Fernández Gallardo, La obra literaria de Alonso de Cartagena (1385-1456). Ensayo de historia cultural, Saarbrücken, EAE, 2012, pp. 33-34. 
ciuitatis tractat in libro Pollitico(rum), quem distinxit per octo libros [...] Et q(uod) ad bene regendum populum multum confert eloq(ue)ncia [...] ideo Philosophus ad complementum documento(rum) moralium composuit quemdam librum, qui appelatur Rethorice, quem distinxit in tres libros [...] Et in hijs q(ui)nq(ue) libris consistit tota philosophia moralis ${ }^{6}$.

Ética, De bona fortuna, Económica, Politica, Retórica: cinco libros -el segundo, apócrifo- que componían un corpus doctrinal que se alzaba así incluso por encima de moralistas y expositores católicos, de manera que la excelencia científica de Aristóteles no habría sido superada por quienes a la luz de la razón habían podido añadir la proveniente de la fe. Ciertamente, don Alfonso había delimitado cuidadosamente el objeto material de la ciencia o doctrina sobre la virtud, las costumbres de los hombres, lo que la situaba en el ámbito de lo natural, regido por principios plenamente inteligibles por medio de la razón. Ese esfuerzo por deslindar con rigor los ámbitos de la naturaleza y de la fe y, consecuentemente, por delimitar la realidad humana sometida a la jurisdicción de la razón, que caracteriza su quehacer intelectual, se revela ya vigoroso en esta su primera obra original. De este modo, el sólido aristotelismo de que hace gala en ella se revela estrechamente unido a esta disposición intelectual. Sus convicciones aristotélicas se hallan, por tanto, en la base de la dirección secularizadora que presenta su pensamiento en sus primeras formulaciones -aun cuando no se trate de una obra propiamente original ${ }^{7}$-.

Unos cinco años más tarde, en las Declamationes $(1430)^{8}$, opúsculo polémico contra la nueva versión latina de la Ética Nicomáquea llevada a cabo por el humanista florentino Leonardo Bruni y publicada en 1416-14179, don Alfonso volvía a mostrar la solidez de su aristotelismo y a propósito nuevamente de la doctrina moral del Estagirita. Ya no se trataba de exponer de

${ }^{6}$ Alfonso de Cartagena, Memoriale virtutum, BNE, ms. 9178, f. 2r-v.

${ }^{7}$ Cosa que el propio Cartagena, que revela honestidad intelectual, reconoce en el prólogo del $\mathrm{Me}$ moriale, declarando que no es autor sino simplemente copista: «Set cum non a me, set ab aliis ingenijs prodita que ad memoriam loq(ue)ndo deuenerant scripture breuissime comendari imperasti, nichil fuit q(uo)d apponeram quia non ut auctoris, set meum vt calamum officium poscebas.» (Memoriale, f. 1r). Véase Luis Fernández Gallardo, La obra literaria, pp. 37-38.

${ }^{8}$ Datación propuesta en Luis Fernández Gallardo, La obra literaria, p. 91. Cuestiona el título, así como el de Declinationes, Juan Miguel Valero Moreno, «Formas del aristotelismo ético-político en la Castilla del siglo XV», en «Aristotele fatto volgare». Tradizione aristotelica e cultura volgare nel Rinascimento, ed. de D. Lines, E. Refini, Pisa, Edizioni ETS, 2014, p. 265.

${ }^{9}$ Sobre el aristotelismo de Bruni véase Gordon Griffiths, James Hankins, David Thompson, The Humanism of Leonardo Bruni, Nueva York, Medieval \& Renaissance Texts \& Studies-The Renaissance Society of America, 1987, pp. 259-262. Valoración de dicha traducción en el contexto de la recepción renacentista de la Ética en David A. Lines, «Aristotle's Ethics in the Renaissance», en The Reception of Aristotle's Ethics, ed. de J. Miller, Cambridge, Cambridge University Press, 2012, pp. 175-177. 
manera accesible los contenidos de la Ética, sino de hacer frente al cuestionamiento de aspectos esenciales del pensamiento ético aristotélico desde supuestos filológicos, la crítica de la traducción latina tradicional. De la divulgación al debate académico: Cartagena se arrogaba la defensa de la doctrina aristotélica construida sobre el texto tradicional, la versión del vetus interpres, universalmente admitido por exégetas y comentaristas latinos, entre los que destacaba Santo Tomás de Aquino, cuyos comentarios había utilizado profusamente en el Memoriale ${ }^{10}$.

La forma en que se manifiesta el aristotelismo de Alfonso de Cartagena en ambas obras viene a corresponder con cuestiones relativas a la recepción de la obra del Estagirita, especialmente en las Declamationes. El punto de partida al respecto es la consideración de la versión latina de la obra de Aristóteles entonces accesible como un corpus textual canónico y, por tanto, incuestionable. No es trivial el símil que establece Cartagena con el canon de libros de leyes, el Corpus Iuris Civilis $^{11}$. Frente a la multitud de numerosas obras jurídicas se alzan con rango canónico las reunidas en el Corpus. De la misma manera, los cinco libros de Aristóteles se erigen en canon de la doctrina moral. Y así como la letra del texto jurídico no admitía discusión, la de la obra aristotélica había asumido el carácter incuestionable de todo fundamento doctrinal ${ }^{12}$.

A la versión latina de la obra de Aristóteles consagrada como texto autoritativo le correspondía una construcción doctrinal consolidada por la tarea exegética de los comentaristas, especialmente por Santo Tomás. Alfonso de Cartagena asume dicha doctrina, que gozaba del rango de autoridad, del mismo modo que los libros de leyes reunidos en el Corpus Iuris Civilis. Eso explicaría que en el Memoriale, aun cuando declare exponer la doctrina contenida en los libros de Aristóteles, inserte amplios fragmentos de los comentarios de

\footnotetext{
${ }^{10}$ Para la asimilación del pensamiento ético aristotélico por parte de Santo Tomás véase Michael Pakaluk, «Structure and Method in Aquinas's Appropiation of Aristotelian Ethical Theory», en Aquinas and the Nicomachean Ethics, ed. de T. Hoffmann et alii, Cambridge, Cambridge University Press, 2013, pp. 33-51. Para una perspectiva general del aristotelismo del Aquinate, Joseph Owens, «Aristotle and Aquinas», en The Cambridge Companion to Aquinas, ed. de N. Kretzmann, E. Stump, Cambridge, Cambridge University Press, 1993, pp. 38-59.

${ }^{11}$ «Et sicut in jure licet sit scripta inme(n)sa multitudo libro(rum), tamen textus iurium in certis $\tau$ determinatis libris continentur qui appellantur corpus. [...] Sic in materia morali hij quinq(ue) libri possunt dici corpus philosophie moralis quia ex istis originem sumpserunt uel cum eis concordare uidentur omn(e)s pene moralium doctrinarum auctores.» (Memoriale, f. 3r).

${ }^{12} \mathrm{Y}$, de hecho, la versión tradicional, aun desdeñada por los humanistas, se mantuvo en realidad como texto de referencia (Luca Bianchi, "Continuity and change in the Aristotelian tradition», en The Cambridge Companion to Renaissance Philosophy, ed. de J. Hankins, Cambridge, Cambridge University Press, 2007, p. 52).
} 
Santo Tomás, como si fueran el texto original. La doctrina adquiere una suerte de autonomía con respecto al tenor literal del texto que la sustenta.

Precisamente eso es lo que iba a cuestionar la nueva versión realizada por Bruni. Una traducción más fiel al original griego, especialmente en el vocabulario relativo a conceptos esenciales, había de conllevar inevitablemente repercusiones de orden doctrinal ${ }^{13}$. Y frente a esa impugnación de la doctrina ética avalada por la tradición y erigida en autoridad alzará su voz alertada Cartagena, quien se percató con clarividencia de las dichas repercusiones.

La línea argumental que sigue en las Declamationes es sumamente reveladora de la índole de su aristotelismo. Va a considerar como piedra de toque de la idoneidad de la traducción su adecuación a la doctrina aristotélica formulada en los términos de la exégesis escolástica. Tal planteo se sustenta en la distinción entre res y verba, la realidad, las cosas y sus relaciones lógicas, por un lado, y su representación verbal, las palabras, por otro. Cartagena dejaba sentadas sus premisas ya en el comienzo del prefacio, al referir la impresión causada por la nueva traducción: deslinde preciso de forma y contenido, identificando aquella con elocuencia («ardorem stili», «eloquentiam») y este con «effectum» ${ }^{14}$.

De este modo, venía a situar la discusión en el plano de la lógica, de la razón, que al ser común a todo el género humano trascendía la diversidad lingüística, que no constituiría sino un accidente con relación a la esencia raciona $l^{15}$. Y en este punto, introduce un razonamiento que constituye el fundamento de su estrategia argumentativa: la excelencia doctrinal, la autoridad que se le reconoce a Aristóteles proviene de su adecuación a la razón, luego lo que concuerde con esta habrá que atribuírselo a él y, por tanto, se supone que así lo habrá expresado en griego, del mismo modo que será correcta la traducción siempre que participe de esa adecuación racional ${ }^{16}$, por lo que

${ }^{13}$ De «cortocuito conceptual» las califica Juan Miguel Valero Moreno, «Formas del aristotelismo», p. 264.

${ }^{14}$ «Cuius cum praefationem legissem et uoluminis aliquos passus sic perfunctorie et superficietenus pertransissem, ardorem stili cognoui et hominis eloquentiam laudaui, effectum uero, quem se consecuturum putaui, abhorrui...» (Alfonso de Cartagena, Declamationes, Prólogo, apud Tomás González Rolán, Antonio Moreno Hernández, Pilar Saquero Suárez-Somonte, Humanismo y teoría de la traducción en España e Italia en la primera mitad del siglo XV, Madrid, Ediciones Clásicas, 2000, p. 164). El término "effectum" es el mismo que poco después utilizaría al citar en castellano la Epistula ad Pammachium de San Jerónimo en el prólogo a su traducción de la Retórica (De inventione) de Cicerón (c. 1431) [Luis Fernández Gallardo, «En torno a los studia humanitatis en la Castilla del Cuatrocientos. Alonso de Cartagena y los autores antiguos», en En la España Medieval, 22 (1999), p. 219].

15 «Ratio enim omni nationi communis est, licet diuersis idiomatibus exprimatur.» (Declamationes, p. 166).

${ }_{16}$ «Cum igitur Aristoteles ipse non rationem ab auctoritate, sed auctoritatem a ratione consecutus est, quicquid rationi consonat haec Aristoteles dixisse putandus est et Graece arbitremur scriptum fuisse, 
para su evaluación podía prescindirse de su compulsa con el texto original griego. Y es que Bruni y su contradictor castellano partían de presupuestos filosóficos, especialmente en lo relativo a la concepción del lenguaje, diferentes: Cartagena se mantiene en el paradigma tradicional conforme al cual el significado de una palabra está fijado en sí mismo por la definición, por lo que permanece inalterable, en tanto que Bruni aquel está determinado por el contexto $^{17}$.

Alfonso de Cartagena rechazaba el acceso filológico al texto latino de la Ética ${ }^{18}$ porque conculcaba la doctrina que se había erigido en autoridad. Ni se le pasó por la cabeza cuestionar dicha doctrina sobre la base de la evidencia filológica. Por otra parte, desde la asunción de la primacía de la res sobre el verbum, el debate doctrinal no podía sustanciarse sino en el plano de la lógica, que trasciende la expresión lingüística concreta. Su aristotelismo ${ }^{19} \mathrm{se}$ manifiesta así como una rigurosa ortodoxia, como construcción doctrinal que no admitía discusión.

\section{En el concilio de Basilea}

Apenas pasados cuatro años desde la redacción del libelo polémico contra Bruni, se le iba a ofrecer la ocasión idónea para la difusión de sus planteamientos frente a una de las más significativas realizaciones del humanismo, la nueva versión latina de la Ética Nicomáquea, uno de los textos mayores de la Antigüedad clásica. Con motivo de su misión diplomática en el concilio de Basilea (1434-1439), entraría en contacto con las más prominentes personalidades del humanismo italiano: Francesco Pizzolpasso -con el que ya hubo de trabar amistad con ocasión de su colectoría-, Ambrosio Traversari, Poggio Bracciolini, Pier Candido Decembrio y, sobre todo, Leonardo Bruni.

Debió de ser factor determinante en la introducción de Cartagena en los cenáculos humanísticos el aristotelismo militante de que hubo de hacer gala

\footnotetext{
quicquid Latinis uerbis translatio nostra sapienter depromit.» (Declamationes, p. 166). En descargo de la parte alícuota de sofistería que presenta el hábil razonamiento, habrá que reconocer que también era cuestión de fe la convicción en la excelencia retórica de Aristóteles que exhibe Bruni, como mostró Jerrold E. Seigel, Rhetoric and Philosophy in Renaissance Humanism. The Union of Eloquence and Wisdom, Petrarch to Valla, Princeton, Princeton University Press, 1968, p. 125.

${ }^{17}$ Ernesto Grassi, Retórica como filosofía. La tradición humanistica, Madrid, Anthropos, 2015, p. 110.

${ }^{18}$ Consciente de que la nueva versión de Bruni era el producto de un nuevo método, fruto de una nueva perspectiva cultural (James Hankins, «The Ethics Controversy», en Humanism and Platonism in the Italian Renaissance, Roma, Edizioni di storia e letteratura, 2007, t. I, p. 201.

${ }^{19}$ Ofrece un balance desde una perspectiva ante todo filológica, antes que propiamente filosófica Ángel Escobar, «El Aristóteles de Alfonso de Cartagena: hacia una valoración de conjunto», en Atalaya 16 (2016) [En línea]. Enlace: <http://atalaya.revues.org/1903> [Consulta: 1/03/2017].
} 
al decidir dar a conocer su libelo contra Bruni. En efecto, don Alfonso pidió a Pizzolpasso que hiciese llegar a Bruni el texto de sus Declamationes ${ }^{20}$, con obvia intención polémica, si no es que pensara ingenuamente que el humanista florentino se iba a rendir a sus argumentos. En este punto surge una cuestión que no se ha planteado: si pudo pasarle el texto a su amigo Pizzolpasso es porque lo había llevado consigo a Basilea, hecho que no se puede explicar sino como deliberado propósito de darlo a conocer fuera de Castilla, lo cual resulta sumamente revelador de una vocación intelectual a la que las obligaciones curialescas no podían limitar. Cartagena se planteó su misión en la embajada conciliar, entre otras cosas, como oportunidad preciosa para satisfacer ese «afán por establecer vínculos con los humanistas transpirenaico ${ }^{21}$.»

Y efectivamente, no desaprovecharía las ocasiones que se le presentaran para el ejercicio de su vocación estudiosa, como pone claramente de manifiesto la lección magistral que pronunció en la universidad de Aviñón, donde hizo un alto la embajada castellana en su camino hacia Basilea, el 19 de julio de 1434. Allí mostró su vasta erudición jurídica, aplicada a la exégesis de una de las leyes más complejas, la ley Gallus contenida en el libro XXVIII del Digesto $^{22}$. El éxito de esta intervención fue rotundo: cautivó al auditorio con sus dotes magistrales, exponiendo con claridad nunca vista los intrincados recovecos normativos del derecho sucesorio ${ }^{23}$.

Así, es probable que al llegar a Basilea contara con un prestigio asentado en una erudición jurídica cumplidamente demostrada en Aviñón y que pronto se iba a confirmar con ocasión del contencioso anglo-castellano sobre cuestión de precedencia. Don Alfonso asumió la responsabilidad de su gestión ${ }^{24}$. La intervención más famosa tuvo lugar el 14 de septiembre de 1434. En el célebre discurso hacía gala de una amplia erudición en la que destacaban las citas de Aristóteles con que se fundamentaba el concepto de nobleza ${ }^{25}$. La impresión que causó fue notable, pues a partir de entonces sería solicitado por el sínodo para el desempeño de gestiones que requerían sólida formación

\footnotetext{
${ }^{20}$ Para el desarrollo de la polémica véase el minucioso análisis de Tomás González Rolán et alii, Humanismo y teoría, pp. 95-103. Cfr. asimismo Luis Fernández Gallardo, La obra literaria, pp. 166-167.

${ }^{21}$ Juan Marichal, «El proceso articulador», p. 22.

${ }^{22}$ Cfr. Digesta 28.2.29. Alfonso de Cartagena, Tractatus super legem Gallus, Archivo de la Catedral de Burgos, cod. 42, ff. 1r-16r. Hay edición moderna y traducción de este texto: Rafael Sánchez Domingo, El Derecho Común en Castilla. Comentario a la Lex Gallus de Alonso de Cartagena, Burgos, Santos, S.L., 2002, pp. 284-388. Véase Luis Fernández Gallardo, Alonso de Cartagena, pp. 135-138.

${ }^{23}$ Álvar García de Santa María, Crónica de Juan II, ed. de A. Paz y Melia, CODOIN, t. C, Madrid, Imprenta de Rafael Marco y Viñas, 1891, p. 394.

${ }^{24}$ Luis Fernández Gallardo, Alonso de Cartagena, pp. 138-158.

${ }^{25}$ Analiza las citas aristotélicas allí insertas Ángel Escobar, «El Aristóteles de Alfonso de Cartagena», $\S 40-44$.
} 
jurídica. Pero igualmente sólido debió de ser percibido su conocimiento de la obra aristotélica, pues los testimonios al respecto dejan plena constancia de ello. Quizá el más conspicuo sea la petición de asesoramiento que le hizo el humanista milanés Pier Candido Decembrio, embarcado entonces en la traducción de La República de Platón: en carta dirigida a Francesco Pizzolpasso el 25 de agosto de 1438, le refiere que había solicitado del prelado burgalés la revisión de su traducción, lo que no se explica sino por la confianza en su dominio de la doctrina política aristotélica ${ }^{26}$.

\section{Un ejercicio académico}

Fue, no obstante, la fama de Cartagena como erudito jurista lo que motivó uno de los debates más interesantes -a la vez que apenas conocido- que sostuvo en Basilea con Ludovico Pontano (1409-1439), a la sazón protonotario apostólico y enviado del rey Alfonso V de Aragón al concilio. El eminente canonista italiano decidió pronunciar una repetitio sobre un capítulo del Liber sextus o Decretales de Bonifacio VIII ${ }^{27}$, convencido de que, dada la abundancia de letrados entre los padres conciliares, redundaría en la difusión de su prestigio como jurista. Y para ello requirió insistentemente de Alfonso de Cartagena que refutara sus conclusiones. El que lo eligiera como contendiente para el debate constituye el más terminante testimonio del prestigio de que gozaba el obispo de Burgos en los medios conciliares. El acto académico hubo de tener lugar entre noviembre de 1436 (incorporación de Ludovico Pontano al concilio) y julio de 1437 (cambio de partido y alineamiento con el sector conciliarista) ${ }^{28}$, dado que la repetitio contiene unos planteamientos favorables al ejercicio de la potestas papal en materia beneficial, lo que no se condiría con las convicciones propias del conciliarismo extremo a que derivó a partir de la fecha señalada.

Hubo de insistir Ludovico de Roma ante el obispo de Burgos ${ }^{29}$ para vencer la reluctancia que este mostraba a bajar a la arena polémica, ejercicio al

${ }^{26} C f r$. Riccardo Fubini, «Tra umanesimo e concili», en Studi Medievali, 7:1 (1966), p. 359. Hay que tener en cuenta que, dado que entonces se asumía que la verdad era única, las discrepancias entre Platón y Aristóteles se hacían remitir no a los contenidos (res o scientia) sino a la expresión verbal (verba) (David A. Lines, «Humanistic and scholastic ethics», en The Cambridge Companion to Renaissance Philosophy, p. 308).

${ }^{27}$ Liber sextus 3.4.23.

${ }^{28}$ Para el cambio de partido del jurista italiano véase Thomas Woelki, Lodovico Pontano (14091439). Eine Juristenkarriere an Universität, Fürstenhof, Kurie und Konzil, Leiden, Brill, 2011, p. 326.

${ }^{29}$ «... rogauit $\mathrm{d}(\mathrm{o}) \mathrm{m}(\mathrm{in}) \mathrm{u}(\mathrm{m})$ Alfonsu(m) Burgens(sem) q(uo)d argueret (con)clusionib(us) p(er) aliq(uo)t dies ante diem respeticio(n)is dat(ae)...» (Alfonso de Cartagena, Tractatus super repetitione Ludovici de Roma, Archivo General de Simancas, Estado. Francia, leg. K-1711, f. 279r [al margen derecho]). 
que, por otra parte, lo empujaba una profunda vocación académica forjada en el paradigma escolástico, en el que la disputatio desempeñaba un papel crucial -la lección de Derecho Civil pronunciada en Aviñón es terminante al respecto. El resultado es un sesudo tratado en que Cartagena despliega su formidable erudición jurídica-.

Y no solo jurídica. En efecto, el Tractatus se presenta como una densa trama de citas autoritativas, ante todo, como no podía ser menos por la índole del contenido, jurídicas, pero no exclusivamente. Sin embargo, de la misma manera que en la argumentación sobre una cuestión de Derecho Canónico, predominan las citas de Derecho Civil, pues don Alfonso era ante todo un consumado legista, tras las autoridades jurídicas figura en número de citas Aristóteles. Así, si el legista se imponía en la consideración de una cuestión propia de la canonística, también estaba presente en ella el estudioso de la filosofía moral, que dentro del paradigma escolástico venía a corresponder con la doctrina ética aristotélica ${ }^{30}$.

El aristotelismo del Tractatus se presenta como un conocimiento profundo tanto de los contenidos doctrinales como de su precisa expresión textual. Nada menos que ocho veces es citada la Ética Nicomáquea. Y no se trata de mera exhibición erudita, de citas que sirvan meramente para recamar con el saber de la Antigüedad la intervención ante los padres conciliares, sino que juegan un papel esencial en la construcción argumentativa del Tractatus: de las ocho citas, seis corresponden a aspectos sustanciales de la argumentación.

En primer lugar, la naturaleza de la concesión beneficial por parte del papa, cuestión en que don Alfonso llega incluso a confutar el propio texto canónico. En efecto, el capítulo sobre el que versaba la repetitio de Ludovico Pontano contemplaba el otorgamiento de la gracia beneficial por parte del papa como manifestación de la virtud de la liberalidad ${ }^{31}$, supuesto que el jurista romano aceptaba sin más, pues formaba parte del texto canónico. Pues bien, Alfonso de Cartagena iba a cuestionar tal planteo al amparo precisamente de la doctrina ética aristotélica. Así, aducía la definición de liberalidad, rigurosamente ajustada al texto aristotélico, para mostrar lo inadecuado de atribuir la concesión de la gracia beneficial a tal virtud, ya que esta se refiere al uso virtuoso del propio dinero o de lo que pueda estimarse en dinero, rasgos ambos que no se dan en la otorgación de la gracia beneficial, pues ni

${ }^{30}$ Saturnino Álvarez Turienzo, «La Edad Media», en Historia de la ética. 1. De los griegos al Renacimiento, ed. de V. Camps, Barcelona, Crítica, 1987, pp. 419-420.

${ }^{31}$ «Si motu proprio alicui, aliquod beneficium obtinenti, conferamus aliud, de illo non habita mentione: non ob hoc gratiam huiusmodi, quae de nostra mera liberalitate processit, invalidam volumus reputari.» (Liber sextus 3.4.23). 
los beneficios son propiedad del papa ni estos pueden valorarse en términos pecuniarios $^{32}$.

A su vez, don Alfonso prolongaba esa línea argumentativa para proponer en lugar de la liberalidad la justicia distributiva como virtud en que se fundamenta la concesión de beneficios por parte del papa. De nuevo la alegación de la doctrina moral del Estagirita permitía establecer un referente aretológico más adecuado al ejercicio de esta manifestación de la potestad pontificia. La colación de beneficios eclesiásticos se asimilaba a la concesión y reparto de honores y responsabilidades públicos ${ }^{33}$, de modo que así se situaba en la órbita de la justicia distributiva. En la medida en que el beneficio podía considerarse un honor, entraba en el ámbito del ejercicio de la justicia distributiva. Es de notar que se omite la dimensión pecuniaria del beneficio eclesiástico, en tanto que este comporta la percepción de rentas, lo cual venía a abundar en el encaje en el ámbito de la justicia distributiva ${ }^{34}$.

Para redondear la argumentación don Alfonso alega el neto deslinde entre las virtudes de la liberalidad y la justicia, remitiendo a la doctrina ética de Aristóteles, a la relativa a ambas virtudes, desarrollada en los libros IV y V, respectivamente, de la Ética Nicomáquea ${ }^{35}$.

Así pues, el principio racional que invalidaba el planteamiento del texto canónico se hacía fundamentar en la autoridad de Aristóteles. De manera que, en última instancia, se estaban confrontando dos tipos de autoridad, jurídica y filosófica, que en el fondo no son sino dos principios de certidumbre, autoridad y razón, los dos pilares de la ciencia jurídica escolástica ${ }^{36}$.

\footnotetext{
${ }^{32}$ «Liberalitas est virtus moralis disponens homine(m), vt recte se habeat circa vsum peccunj(arum) et alio(rum) exterioru(m) bono(rum), quoru(m) dignitas pecunia seu numismate mensuratur, vt patet $\mathrm{p}(\mathrm{er})$ Aristo(telem) in iiij ${ }^{\circ}$ Ethicor(rum). Set b(e)n(e)ficia ecc(les)iastica non sunt hui(us)cem(od)j cu(m) nec sint in dominio P(a)pe nec possint peccunja extimari...» (Tractatus, f. 283v). Cfr. Aristóteles, Ética Nicomáquea, 1119b, trad. J. Pallí Bonet, Madrid, Gredos, 1988, p. 208. En la definición que da Cartagena de la liberalidad se observan ecos verbales del texto aristotélico: «Laudatur enim liberalis [...] circa dacionem pecuniarum, et sumpcionem; magis autem in dacione. Pecunias autem dicimus omnia quorumcumque dignitas numismate mensuratur.» (Aristoteles Latinus, XXVI, 1-3, Ethica Nicomachia, translatio Roberti Grosseteste Lincolniensis, IV, 1, ed. de R. A. Gauthier, Leiden-Bruselas, Brill-Desclée de Brouwer, 1972, p. 202).

${ }^{33}$ «Beneficioru(m) aut(em) collacio et omniu(m) hono(rum) et oneru(m) publico(rum) distribucio $\mathrm{p}(\mathrm{er})$ tinet ad iustitia(m) distributiua(m), vt patet $\mathrm{p}(\mathrm{er})$ Aristo(telem) in v Ethico(rum).» (Tractatus, f. 283v). Cfr. Aristóteles, Ética Nicomáquea, 1130b-1131a, p. 242.

${ }^{34}$ La letra del texto aristotélico así lo avalaría: «... una quidem est species que in distribucionibus honoris vel pecuniarum vel aliorum quecumque partibilia communicantibus urbanitate.» (Ethica Nicomachia, $\mathrm{V}, 5)$.

${ }^{35}$ «Iusticia aut(em) et liberalitas sunt diu(er)sse et distincte virtutes morales tum respectu subjecti $\mathrm{q}($ ua)m ectia(m) s(e)c(un)d(u)m alias multas consideracio(n)es, quas hic expr(ri)mere e(ss)et longe p(er) egrinari a p(ro)po(s)ito, s(ed) patent in iiij et v $^{\circ}$ Ethico(rum).» (Tractatus, f. 283v). Cfr. Aristóteles, Ética Nicomáquea, 1119a-1122a, 1129a-1131a.

${ }^{36}$ Tal y como lo formularía en forma aforística el gran jurista inglés Sir Edward Coke (1552-1634) en sus Institutes of the Laws of England: «Ratio et auctoritas, duo clarissima lumina mundi.» [citado por
} 
Alfonso de Cartagena no dudaba en cuestionar la autoridad jurídica desde fundamentos racionales. Pero, a su vez, era plenamente consciente del desafío que esto suponía para el orden social, regido por el incuestionable principio de autoridad. De ahí que, respondiendo a la objeción que se le pudiera hacer en este sentido, se apresure a apelar en el mismo inicio de su respuesta a la idea de libertas scholastica ${ }^{37}$, que viene a constituir un ámbito de libre discusión académica sin ulteriores consecuencias, de libre especulación sin repercusiones de orden práctico, y que, por tanto, puede ser compatible con el dócil sometimiento al orden establecido -aunque no hay que perder de vista la efectividad crítica que podía asumir ${ }^{38}$.

Y es que, efectivamente, el cuestionamiento del capítulo de las Decretales conllevaba una limitación de la potestas pontificia, en la medida en que planteaba una restricción de su facultad de conceder gracias beneficiales. En el preciso contexto conciliar no se trataba de una cuestión meramente académica, sino que se incardinaba de lleno en el debate conciliar, dentro del cual no era asunto menor el relativo a los beneficios eclesiásticos.

La rigurosa aplicación de la doctrina moral aristotélica exigía la adecuada correspondencia de las figuras del Derecho Canónico con las virtudes a cuyo ejercicio podían asignarse. Así, don Alfonso acudía a la virtud de la epiqueya para confirmar la diferencia entre dispensa y gracia beneficial: a aquella le correspondía dicha virtud, en tanto que esta se situaba en el ámbito de la justicia distributiva. El diferente referente aretológico permitía establecer el adecuado deslinde entre ambas figuras del Derecho Canónico ${ }^{39}$. Frente a la matizada relación de ambas virtudes que proponía Aristóteles, Cartagena cargaba el acento en la neta diferenciación.

Por tener menor repercusión argumentativa resulta, empero, de mayor significación el recurso a la doctrina aristotélica acerca de la prudencia, en la

\footnotetext{
George Makdisi, «The Scholastic Method in Medieval Education: An Inquiry into its Origins in Law and Theology», en Speculum, 49:4 (1974), p. 660].

37 «In omnibus aut(em) hijs et in singulis eor(um) semp(er) reue(er)encia debita premissa et sub scolastici libertate loquendo vident(ur) tam text(us) iste $\mathrm{q}(\mathrm{ua}) \mathrm{m}$ conclusiones falso et inepte $\mathrm{p}$ (ro)cedere...» (Tractatus, f. 280r). Sobre este concepto véase Laetitia Boehm, Libertas scholastica und Negotium scholare. Entstehung und Sozialprestige des akademischen Standes im Mittelalter, Limburgo del Lahn, C.A. Starke Verlag, 1970.

${ }^{38}$ Hans-Jörg Gilomen, «Conciliar Burocracy», en A Companion to the Council of Basel, ed. de Michiel Decaluwe et alii, Leiden, Brill, 2017, pp. 180-182.

${ }^{39} \ll \mathrm{B}(\mathrm{e}) \mathrm{n}(\mathrm{e})$ ficioru(m) $\mathrm{p}(\mathrm{ro})$ uissio regulari debet $\mathrm{p}(\mathrm{er})$ iusticia(m) distribitiua(m), vt supra dixim(us).

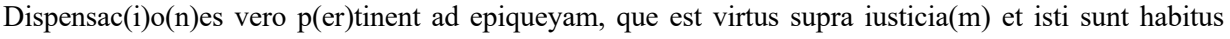
distincti, vt manifeste p(ro)bat(ur) p(er) Aristo(telem) in $\mathrm{v}^{\mathrm{o}}$ Ethi(corum).» (Tractatus, f. 284v). Cfr. Aristóteles, Ética Nicomáquea, 1137a, p. 262.
} 
medida en que esta desempeña un papel axial en el sistema ético del Estagirita $^{40}$. El rigor dialéctico de don Alfonso le llevaba a remachar la confutación de la atribución de las gracias beneficiales al ejercicio de la liberalidad. Así, incluso concediendo tal extremo, concluía que resultaba improcedente sobre la base del principio aristotélico de que la prudencia constituye el fundamento de la virtud ${ }^{41}$. En este punto, más que a la literalidad del texto aristotélico, Cartagena se acogía a la doctrina, que se formulaba en términos más matizados ${ }^{42}$. Es más: antes que a la propia doctrina del Estagirita, en realidad reproducía a la letra la de Santo Tomás, ciertamente de claro cuño aristotélico ${ }^{43}$. Esto es, cita a Aristóteles por medio del Aquinate. Este hecho es sumamente revelador de la jerarquía de autoridades que parece establecerse en el Tractatus: diríase que le concede mayor fuerza suasoria al Estagirita que al Doctor Angélico, cuya Summa Theologiae es asimismo citada expresamente. Mejor, ante los padres conciliares estimaría que iba a ser más convincente Aristóteles, que personificaba la razón natural, frente a la ciencia teológica. A su vez, es asimismo revelador de la nueva estimación del saber de la Antigüedad, cuyo conocimiento se amplió considerablemente con ocasión del concilio basiliense.

\section{En el epicentro del debate eclesiológico}

De mayor trascendencia sería la apelación a la autoridad de Aristóteles en una importante intervención de Alfonso de Cartagena en el concilio de Basilea: la que tuvo lugar en el curso de las decisivas sesiones iniciadas el 15 de abril de 1439, en que se debatió la deposición del papa Eugenio IV. Se trata de una pieza oratoria construida con solidísima erudición no solo jurídica, sino filosófica. No se conserva el texto del discurso ${ }^{44}$, pero el testimonio de dos grandes historiadores del concilio, Eneas Silvio Piccolomini, eximio hu-

${ }^{40}$ Emilio Lledó, «Aristóteles y la ética de la "polis"», en Historia de la ética, ed. de V. Camps, pp. 173-179. El tema de la prudencia está presente en toda la obra de Aristóteles para Pierre Aubenque, La prudence chez Aristote, París, PUF, 2014, p. 174-177.

${ }^{41}$ «Ectia(m) si vellim(us) tollerare q(uod) gracia beneficialis aplicetur liberalitati, q(uod) tollerand(um) non est adhuc, ista racio videtur concludere cont(ra) se ip(s)am. Q(uo)d deducitur sic. Q(ua)nto magis actus app(ro)pinquat virtuti tanto magis debet regi p(er) prudenciam. Q(uo)d p(ro)bat(ur) ex eo quia nulla virtus moralis esse pot(est) sine prudentia, vt patet p(er) Aristo(telem) in vj ${ }^{\circ}$ Ethico(rum).» (Tractatus, f. 283v).

${ }^{42} \mathrm{Cfr}$ : «Propter quod aiunt omnes virtutes prudencias esse, et Socrates sic quidem recte querebat, sic autem peccabat. Quoniam quidem enim prudentes existimabat esse omnes virtutes, peccabat. Quoniam autem non sine prudencia, bene dicebat.» (Ethica Nicomachia, VI, 17, p. 270).

${ }^{43} C f r$ : «Sine prudentia quidem esse non potest moralis virtus...» (Santo Tomás de Aquino, Summa Theologiae, $\mathrm{I}^{\mathrm{a}}-\mathrm{II}^{\mathrm{ae}}$, q. 58, a. 4, arg. 1).

${ }^{44}$ Extraña la ausencia de esta importante pieza oratoria en el mencionado códice burgalés que contiene abundante documentación relacionada con la actividad conciliar de Alfonso de Cartagena (Archivo de la Catedral de Burgos, cod. 42). 
manista y futuro papa Pío II, y Juan de Segovia, eminente teólogo -a los que, por cierto, unió estrecha amistad anudada en Basilea $^{45}$-, permite reconstruir las líneas maestras del contenido y, sobre todo, el impacto que hubo de tener entre los padres conciliares.

\subsection{El testimonio de Piccolomini}

Eneas Silvio Piccolomini escribió su De gestis en 1439, al calor de los hechos narrados, en la medida en que centra su atención en los acontecimientos que se desarrollaron en torno al debate sobre la resolución de las tres veritates y la elección del papa Félix V, del que era a la sazón secretario (octubre de 1438 y noviembre de 1439$)^{46}$. Manifiesta un acusado interés por referir los discursos que se pronunciaron en el curso de las sesiones conciliares, que es deudor no tanto de su probidad como historiador, cuanto de sus inquietudes humanísticas, en la medida en que la introducción de arengas y discursos constituía uno de los recursos dilectos de la historiografía humanística, que aspiraba a la imitación de quien era considerado modelo de la escritura de la historia, Tito Livio ${ }^{47}$. De ahí que tanto como a los contenidos de los discursos, Piccolomini se muestre atento a los aspectos formales.

El futuro papa Pío II muestra en todo momento una abierta simpatía hacia Alfonso de Cartagena, a quien siempre menciona con términos elogiosos, por lo que las referencias a su intervención tienen un continuo tono encomiástico. Así, al introducir la pieza oratoria del prelado burgalés, incluye la siguiente aposición: «inter Prelatos apprime doctus» ${ }^{48}$. No es casual que la primera observación se refiera al rigor formal que preside el discurso de don Alfonso: la agrupación de las conclusiones en dos modalidades, generales y personales ${ }^{49}$.

${ }^{45}$ La estudia a través del intercambio epistolar entre ambos Darío Cabanelas Rodríguez, Juan de Segovia y el problema islámico, Madrid, Facultad de Filosofía y Letras, 1952, pp. 225-235.

46 Jesse D. Mann, «Histories of the Council» en A Companion to the Council of Basel, pp. 60-61. Véase asimismo Emily O'Brien, «Aeneas Sylvius Piccolomini and the Histories of the Council of Basel», en The Church, the Councils \& Reform. The Legacy of the Fifteenth Century, ed. de G. Christianson et alii, Washington, D.C., The Catholic University of America Press, 2008, pp. 60-81.

${ }^{47}$ Bertold Ullman, «Leonardo Bruni and Humanistic Historiography», en Studies in the Italian Renaissance, Roma, Edizioni di Storia e Letteratura, 1955, pp. 331-333; Eric W. Cochrane, Historians and Historiography in the Italian Renaissance, Chicago, The University of Chicago Press, 1981, pp. 5-6. Empero, tampoco hay que perder de vista el importante papel que jugaron en Basilea la oratoria y la retórica: «... as at democratic Athens, rhetoric played an important role.» (Antony Black, Council and Commune. The Conciliar Movement and the Council of Basle, Londres, Burns \& Oates, 1979, p. 28).

${ }^{48}$ Eneas Silvio Piccolomini, Commentariorum historicorum libri III de Concilio Basileensi, Helmstadt, Impensis Joh. Melchioris Sustermanni, 1700, p. 15.

${ }_{49}$ «Conclusiones bifariam divisit, aliasqve generales, aliasqve personales appellans...» (Piccolomini, Commentariorum, p. 15). 
Tras ponderar la erudición jurídica exhibida ${ }^{50}$, se extiende en aquella faceta del saber y la ciencia del prelado burgalés que hubo de llamarle más la atención, el uso de la doctrina aristotélica, erigida en el argumento clave de la tesis sostenida con relación a la ardua cuestión debatida, las relaciones entre pontificado y concilio en el marco constitucional de la Iglesia. Alfonso de Cartagena afirmó la superioridad del concilio sobre el papa $^{51}$, mas, al arrimo de la autoridad de Aristóteles, matizaba la posición constitucional del papa:

... Physica etiam ratione asseruit; adductoqve in testem summo omnium Philosophorum Aristotile, dicebat, in regno bene instituto illud in primis desiderari, ut plus Regnum posset qvam Rex, si contra repereritur, id non regnum, sed Tyrannidem dici debere. Sic etiam sibi de Ecclesia videri, qvod eam plus suo Principe, id est Papa, posse oporteret... ${ }^{52}$

Es de notar la apelación a la physica ratio, esto es, a la razón natural, el instrumento cognitivo de la filosofía, cuyo cultor más destacado es Aristóteles. Al situarse tras la rápida referencia a las autoridades jurídicas cobra especial realce la cita del Estagirita. Más que la identificación de la cita, que remite a la Política, le interesa a Piccolomini la naturaleza argumentativa de la autoridad aducida, fundada en la razón. En efecto, la cita aristotélica puesta en boca de Cartagena corresponde a las consideraciones que hace el Estagirita acerca de las clases de regímenes políticos y sus correspondientes desviaciones. La de la monarquía es la tiranía, definida como «monarquía orientada al interés del monarca», en lugar del bien común, meta de todos los regímenes $^{53}$. Diríase que Piccolomini quedó cautivado por la estrategia argumentativa basada en la transferencia de principios naturales (la ratio physica) al debate eclesiológico, de naturaleza más bien jurídica y teológica, que se concreta en la aplicación de la filosofía política al análisis constitucional de la Iglesia.

Mas tal argumento, fundado en la autoridad de Aristóteles, ya había sido esgrimido por Pierre d'Ailly (1351-1420) en su Tractatus de ecclesiastica potestate, uno de los teólogos más destacados del Concilio de Constanza y

${ }^{50}$ Despachada apresuradamente en cláusula subordinada: «... idqve postqvam iure divino humanoqve probavit...» (Piccolomini, Commentariorum, p. 15).

${ }^{51}$ «Plurimumqve illic immorari voluit, ut sacrum Concilium supra Papam esse ostenderet...» (Piccolomini, Commentariorum, p. 15).

52 Piccolomini, Commentariorum, p. 15.

${ }^{53}$ Aristóteles, Politica, 1279b, trad. C. García Gual-A. Pérez Jiménez, Madrid, Alianza Editorial, 1991, p. 120. 
precursor del pensamiento conciliar ${ }^{54}$. Así pues, Piccolomini alababa en el prelado burgalés precisamente aquella faceta de su discurso que presentaba un cariz marcadamente conciliarista.

A su vez, en la afirmación de la conveniencia de la preeminencia de la Iglesia sobre el papa cabe reconocer otro locus aristotélico, solo que ya directamente referido al contexto eclesiológico. Solo el testimonio más detallado de Juan de Segovia permite identificar la cita en cuestión ${ }^{55}$, oculta tras la apretada síntesis que Piccolomini hace del contenido del discurso de Cartagena.

Más que los aspectos propiamente doctrinales, a Piccolomini parecen atraerle los retóricos. Ciertamente, la noticia que ofrece del discurso de Alfonso de Cartagena -y de los demás reseñados en su obra- tiene todo el sabor de testimonio personal ${ }^{56}$. Es de suponer que tomaría notas de las intervenciones a las que asistió. Pues estas, antes que la propia documentación conciliar, parecen ser la fuente de su historia, al menos del discurso de Cartagena, lo que se condice con la naturaleza genérica de su relato, commentarii, que se ha caracterizado por su provisionalidad, frente al rigor de la historia ${ }^{57}$. Y en efecto, parece recoger si no la central, una de las tesis principales del discurso, la superioridad del concilio sobre el papa, para, a continuación, ponderar sus cualidades retóricas, extendiéndose en el efecto ejercido sobre el auditorio $^{58}$, piedra de toque de la excelencia oratoria.

Por tanto, no le interesaba tanto la precisión erudita de la cita de Aristóteles -que de seguro tendría el discurso de don Alfonso, como solía en obras de esta naturaleza, especialmente cuando la cita tenía una clara función argumentativa, no ornamental-, por lo que no indica qué obra de Aristóteles es la aducida.

\footnotetext{
${ }^{54}$ Hermann Josef Sieben, «Aristoteles bei Konstanzer und Basler Konziliaristen», en Aristotelica et Lulliana: magistro doctissimo Charles H. Lohr septuagesimum annum feliciter agenti dedicata, ed. de F. Domínguez, Steenbrugge, In Abbatia S. Petri, 1995, pp. 209-210. Para la contribución de Pierre d'Ailly al pensamiento conciliar véase Antony Black, Council and Commune, pp. 19-25.

55 «Sic etiam sibi de Ecclesia videri, qvod eam plus suo Principe, id est Papa, posse oporteret...» (Piccolomini, Commentariorum, p. 15). Cfr. Aristóteles, Politica, 1266b, p. 141.

${ }^{56}$ Ya ponderó la calidad de testimonio vívido de los Commentaria Georg Voigt, Enea Silvio de'Piccolomini, als Papst Pius der Zweite, und sein Zeitalter, Berlín, Georg Reimer, 1856, p. 228. A su vez, a propósito de los Commentaria, ya destacó su «eye for picturesque details and striking situations» Cecilia M. Ady, Pius II (Aeneas Silvius Piccolomini). The Humanist Pope, Londres, Methuen \& Co., 1913, p. 291.

${ }^{57}$ Gary Ianzitti, «I “Commentarii”: appunti per la storia di un genere storiografico quattrocentesco», en Archivio Storico Italiano, 554 (1992), pp. 1029-1063 (especialmente pp. 1035-1036).

${ }^{58}$ «... quem sermonem sic ornate, sic svaviter disputavit, sic docte atqve verifice, ut omnes ab ejus ore avide dependerent, jam non (ut in aliis fit) orationis finem, sed longam continuationem desiderantes...» (Piccolomini, Commentariorum, p. 15).
} 


\subsection{El testimonio de Juan de Segovia}

Muy diferente es la información que de la misma pieza oratoria ofrecería Juan de Segovia en su magna historia del concilio. Dos perspectivas y, sobre todo, dos temples historiográficos completamente distintos. Egregio teólogo y una de las mentes más lúcidas del concilio, Segovia abordaba la exposición acerca de su coterráneo con la objetividad, al menos aparente, de quien se proponía una narración veraz del desarrollo del sínodo basiliense. Compuso su historia en su retiro del priorato de Aitón, en Saboya, entregado a su incoercible vocación estudiosa, dedicando sus últimas energías intelectuales a la solución pacifista del problema islámico ${ }^{59}$.

Al narrar las turbulentas sesiones, iniciadas el 15 de abril de 1439, en las cuales se discutió acaloradamente si el papa Eugenio IV había incurrido en herejía y por tanto su deposición, dedica Segovia el capítulo XXX del libro XIV a los debates conciliares al respecto. El detalle con que se reproducen las diferentes intervenciones revela no solo al testigo -y asimismo actor- de los hechos narrados, sino al probo historiador que compone su relato magníficamente pertrechado de documentos, ya sea versiones escritas de dichas intervenciones o las notas que es probable tomara de ellas ${ }^{60}$. De hecho, su espléndida biblioteca, que donaría a su alma mater, la Universidad de Salamanca, contenía abundante documentación relativa al sínodo basiliense: actas, decretos, epístolas, concordata, orationes, en fin, una imponente masa de documentos que evidencia el hondo compromiso del gran teólogo con el concilio y la reflexión eclesiológica ${ }^{61}$.

La exposición de la intervención de Alfonso de Cartagena presenta especial interés por el detalle con que se indican las autoridades aducidas para sustentar las tesis sostenidas, gracias al rigor historiográfico que preside su magna obra. En primer lugar, se refiere al imponente cúmulo de citas jurídicas

\footnotetext{
${ }^{59}$ Resulta emocionante el testimonio personal de su vocación intelectual en carta dirigida a Eneas Silvio: «Videns igitur me gravissima egritudine laborantem, diebus ultimis vite mee, sic quod vix queam calamum notule huius imprimere...» (apud Darío Cabanelas Rodríguez, Juan de Segovia, p. 344). Para esta etapa de la vida de Segovia véase Darío Cabanelas Rodríguez, Juan de Segovia, pp. 71-74 y Uta Fromherz, Johannes von Segovia als Geschichtsschreiber des Konzils von Basel, Basilea-Stuttgart, Helbing \& Lichtenhahn, 1960, pp. 37-42 (la sección “Aiton” de la relación de obras de Segovia, p. 155, muestra la fecundidad literaria de esta etapa).

${ }^{60}$ Tres son las fuentes esenciales de la historia de Segovia: en primer lugar, los protocolos oficiales y colecciones de decretos del concilio; en segundo, notas del propio autor; en tercero, fragmentos de actas, cartas llegadas al sínodo (Uta Fromherz, Johannes von Segovia, p. 71).

${ }^{61} C f r$. los números 49 a 55 y 59 de la escritura de donación (Benigno Hernández Montes, Biblioteca de Juan de Segovia. Edición y comentario de su escritura de donación, Madrid, CSIC, 1984, pp. 95-97). Ofrece un cumplido análisis de las ideas de Juan de Segovia Antony Black, Council and Commune, pp. 118-193.
} 
y filosóficas que alegó el prelado burgalés para sustentar la naturaleza monárquica del gobierno de la Iglesia:

Abinde Burgensis episcopus, exordio sumpto ad materiam de potestate pape et concilii induci posse iura canonica antiqua, antiquissima, noua et nouissima, videlicet et extrauagantes, eam specialiter, que incipit 'vnam sanctam', affirmantem, quod de neccessitate salutis omnis racionalis creatura subiecta est summo pontifici, iura quoque codicis et auctenticorum, naturalis eciam et moralis doctrinam philosophie inducebat, quomodo monarchia a legibus esset libera, policiam vero ecclesiasticam optimam fuisse institutam, quia monarchicam... ${ }^{62}$

Llama la atención el detalle con que se enuncian las distintas auctoritates del Derecho Canónico y Civil -a las que, ciertamente, se añade la filosofía natural y moral-. Conforme al rigor que preside su exposición, Juan de Segovia distingue entre la tesis relativa a la soberanía pontificia, sustentada en el Derecho Canónico, y la referida a la constitución política de la Iglesia, a su naturaleza monárquica, fundamentada en el Derecho Civil y la filosofía natural y moral. La forma en que se refiere a las fuentes canonísticas de la doctrina de la superioridad del papa parece traslucir cierto deje irónico, cuando no prevención ante la alegación de uno de los pilares de la concepción autocrática del papado, la bula Unam Sanctam. La acumulación de los diferentes tipos de textos canonísticos más que a ponderar la ciencia jurídica del obispo de Burgos apuntan a destacar una suerte de derroche erudito, en la medida en que el teólogo que consideraba que la cuestión de la autoridad de la Iglesia constituía una verdad de derecho divino y había de ser estudiada a partir de fuentes escriturarias ${ }^{63}$ consideraría inane el aporte de la ciencia canonística.

Sin embargo, para el tratamiento de la cuestión relativa a la constitución monárquica de la Iglesia -que Segovia no dejaba de aceptar ${ }^{64}$, opone el Derecho Civil y la filosofía. Bajo la expresión «doctrina de filosofía natural y moral» es lo más probable que Segovia se refiriera a la Política y a la Ética de Aristóteles, pero tal vez no tanto a los respectivos textos genuinos, obviamente en su versión latina, sino a los comentarios: el texto y su glosa canónica, la de Santo Tomás de Aquino - que ya utilizara Cartagena, puesto a exponer la doctrina ética del Estagirita, en su Memoriale virtutum, como si de la propia obra aristotélica se tratara-.

\footnotetext{
${ }^{62}$ Juan de Segovia, Historia Gestorum Generalis Synodi Basiliensis, Monumenta Conciliorum Generalium seculi decimi quinti. Concilium Basiliense, vol. II, Viena, Typis Adolphi Holzhausen, 1886, p. 261.

${ }^{63}$ Antony Black, Council and Commune, p. 128.

${ }^{64}$ Uta Fromherz, Johannes von Segovia, pp. 139-140.
} 
Mas a continuación incluye una matización de la tesis enunciada, la distinción entre la superioridad del papa sobre cada uno de los individuos y sobre el conjunto de la Iglesia ${ }^{65}$, que se fundamenta en el Derecho Civil y en Aristóteles. $\mathrm{Y}$ en este punto introduce la referencia más exacta de las fuentes de cualquiera de las intervenciones de los padres conciliares:

... que responsio fundari posset in iure ciuili, de quo allegauit glo. Accursii ff. de ..., eciam in $\mathrm{III}^{\circ}$ politicorum docente Aristotele, quod ad bonum monarcham pertinent, potenciorem esse quolibet singulorum sui principatus, sed non ipso regno suo aut principatu... ${ }^{66}$

Y seguidamente, tras la exposición del contenido del locus aristotélico aducido, reproduce Segovia el tenor literal de la fuente:

... verba autem Aristotelis hec sunt: «Oportet enim ipsum quidem regem habere potenciam, esse autem tantam potenciam, vt sit ea, que singulorum et vnius et simul plurium maior; ea autem, que multitudinis, minor.» ${ }^{67}$

Se trata de un proceder excepcional, pues Segovia no hace citas literales de las intervenciones. ¿Tendría delante la versión escrita del discurso de don Alfonso o incluyó la cita por su cuenta, dada la importancia del argumento esgrimido $^{68}$ ? En cualquier caso, la cita remite a la versión latina tradicional de Guillermo de Moerbeke (1215-1286), puntualmente reproducida en su tenor literal ${ }^{69}$. Aun concediendo que se trate de una interpolación del propio Segovia, al margen de la genuina textualidad del discurso de Cartagena, este manejaría asimismo dicha versión: en primer lugar, porque tomaría el texto aristotélico del incluido en los comentarios de Santo Tomás; en segundo, porque es muy poco probable que le hubiese llegado la entonces recentísima nueva versión latina de Leonardo Bruni, elaborada en 1438, tras un

${ }^{65} « \ldots$ sed quod ad hec iam assuetum foret responderi, verum esse respectu singulorum, papam a nemine iudicari posse, non vero respect vniversitatis ecclesie...» (Juan de Segovia, Historia Gestorum, p. 261).

${ }^{66}$ Juan de Segovia, Historia Gestorum, p. 261. Cfr. Aristóteles, Política, 1266b, p. 141.

${ }^{67}$ Juan de Segovia, Historia Gestorum, p. 261.

${ }^{68}$ Pues el propio Segovia utilizaría asimismo este locus aristotélico (Hermann Josef Sieben, «Aristoteles», p. 216).

${ }^{69}$ Cfr. Aristotelis Politicorum antiqua translatio, III, XIV, apud Aristóteles, Politicorum siue de Republica libri octo, Venecia, Apud Ivntas, 1568, f. 146b (se trata de una utilísima edición de la versión latina de Leonardo Bruni, en la que se intercalan los comentarios de Santo Tomás, y de la antiqua translatio). Esta fue realizada en torno a 1260 y tuvo una amplia difusión unida a los comentarios de Santo Tomás [Martin Grabmann, «Forschungen über die lateinische Aristoteles-Übersetzungen des XIII. Jahrhunderts», en Beiträge zur Geschichte der Philosophie des Mittelalters, 17:5-6 (1916), pp. 239-240]. 
intermedio platónico, aunque ya les unía una entrañable amistad, superado el encono polémico en que se habían enzarzado, la Controversia Alphonsiana.

La constatación de este hecho -que no ha tenido en cuenta Sieben por cuanto confronta la cita con el texto original griego- permite limitar el grado de «sobreinterpretación» que este estudioso ha achacado al uso de la cita de Aristóteles que hace Cartagena ${ }^{70}$. Si en lugar de compulsarse con el original griego se hace con la antiqua translatio, se pone de manifiesto la legitimidad del salto exegético que permite la aplicación del texto aristotélico a la tesis planteada. Pues efectivamente el término «potentiam», el escogido por Guillermo de Moerbeke, por su relación con potestas justificaba referirlo no solo al poderío militar ${ }^{71}$, que es el ámbito de consideración del texto de la Política, sino al poder político en general.

\subsection{Cartagena, conspicuo aristotélico}

Los testimonios de ambos historiadores se complementan pues cada uno cita el locus aristotélico que debió de llamarle más la atención, sendas citas de la Política. El hecho de que ambos escribieran sus historias desde una posición de comprensión, favor o abierta simpatía hacia la causa conciliar hubo de ser un poderoso acicate para resaltar la sólida argumentación de las tesis de Cartagena, más que el reconocimiento y encomio de la erudición del obispo de Burgos -ausente, por otra parte, en Juan de Segovia, que no ocultaba cierta impaciencia ante la inacabable alegación de autoridades del Derecho Canónico-. Debieron sin duda encontrar en el recurso a la ciencia, representada por el corpus doctrinal aristotélico, un fundamento clave para la legitimación del concilio o, cuando menos, de una instancia limitadora del poder papal.

Del cotejo de ambas exposiciones se colige que la posición sostenida por Alfonso de Cartagena representaba un esfuerzo por conciliar los dos partidos enfrentados. Así, el punto de partida es una inequívoca afirmación de la tesis papista: la consustancial naturaleza monárquica de la constitución de la Iglesia. Y en este punto cabría observar la habilidad dialéctica del obispo de Burgos para sortear el maximalismo extremo y buscar una suerte de tercera vía, pues, por un lado, reconoce y admite las formulaciones más netamente

${ }^{70}$ «Ein Blick in moderne Übersetzungen und Kommentare der angezogenen Stelle zeigt, da $\beta$ der Bischof von Burgos den text überinterpretiert.» (Hermann Josef Sieben, «Aristoteles», p. 211).

${ }^{71}$ De hecho, Bruni, en lugar de "potentia" utiliza el término "vires", más cercano al original. Cfr: $\ll \mathrm{Na}(\mathrm{m})$ oportet ipsum vires habere: sed tales, vt vnoquoq(ue) separatim \& simul pluribus potentior sit: populo t(ame)n sit impotentior...» (Aristóteles, Politicorum siue de Republica libri octo, f. 49a). El comentario de Santo Tomás abundaba en la idea de "potentia". 
autocráticas de la autoridad monárquica, la exención de la ley, que tenía el refrendo del Derecho Romano ${ }^{72}$. A continuación, empero, se sostiene la idoneidad del régimen monárquico de la Iglesia. Y en este punto adquiere especial importancia el recurso a la autoridad de Aristóteles, que, frente a los argumentos autocráticos que proporcionaba la ciencia jurídica, ofrecía un indiscutible fundamento limitador del ejercicio del poder del monarca, el que residía en la propia naturaleza del régimen político de la monarquía: en cuanto tal poseía unos límites que lo diferenciaban netamente de la tiranía.

A este respecto, ofrece una exposición más matizada Juan de Segovia. La cuestión tratada por el obispo de Burgos versa «de potestate pape et concilii». Por un lado, la tesis autocrática, que atribuye cualidad de monarca al papa, sustentada por el Derecho Canónico; por otro, la limitadora del poder papal, fundamentada en Aristóteles. Piccolomini, en cambio, presentaba una exposición menos matizada del contenido ideológico del discurso de Cartagena, destacando los argumentos limitadores del poder papal -reconociendo entre ellos la preeminencia de la doctrina aristotélica- interpretándolos como inequívoca afirmación de la superioridad del concilio sobre el papa, aserción que realza como si de la tesis central se tratara ${ }^{73}$.

En cualquier caso, los dos historiadores, con diferentes matices y énfasis, concedían un papel esencial a la doctrina aristotélica en el argumentario del prelado burgalés. Diríase que ambos dejaban entrever admiración -y en el caso de Piccolomini, abierta simpatía- hacia su calidad dialéctica, por cuanto se ofrecía un fundamento científico, erigido sobre la razón natural (physica ratio), a los argumentos limitadores de la potestad pontificia.

Don Alfonso transfería los principios de la ciencia política a la reflexión eclesiológica. Ahora bien, la plena eficacia argumentativa de los loci aristotélicos aducidos descansaba sobre un supuesto, que no queda claro que admitiese. Es obvio que el papa es el homólogo del monarca y la Iglesia del reino, pero lo que ya no es del todo seguro es que para Cartagena la Iglesia esté representada por el concilio ${ }^{74}$, tal y como quedó establecido en el decreto constanciense Haec sancta, consagrado por el sínodo basiliense como artículo de fe, una de las tres veritates proclamadas en la sesión XXXIII, celebrada

${ }^{72}$ «... quomodo monarchia a legibus esset libera...» (Juan de Segovia, Historia Gestorum, p. 261). Cfr. «Princeps legibus solutus est.» (Digesta 1.3.31).

${ }^{73}$ Piccolomini, Commentariorum, p. 15,

${ }^{74}$ Los conciliaristas basilienses llegaron a situar la iglesia universal en el mismo plano que la asamblea eclesiástica, transfiriendo la soberanía atribuida a la Iglesia al concilio (véase el riguroso análisis de Antony Black, Monarchy and Community. Political Ideas in the Later Controversy (1430-1450), Cambridge, Cambridge University Press, 1970, pp. 15-22). 
el 26 de mayo de $1439^{75}$. Ciertamente, la dogmática católica rechazó como herético el decreto del concilio de Constanza, pero en los turbulentos años del conflicto entre pontificado y concilio no era una cuestión cerrada la de la supremacía de uno u otro. El obispo de Burgos bien pudo conceder con las cautelas propias de su ponderado talante el carácter representativo del concilio, máxime teniendo en cuenta la amplia representación de todos los órdenes y rangos de la Iglesia ${ }^{76}$.

\section{Conclusión}

Se revela de este modo una dimensión del aristotelismo de Cartagena de sumo interés: el subordinado a la fundamentación de su pensamiento, expuesto en el ejercicio de su actividad como eclesiástico, en una cuestión y en un momento histórico crucial: la definición de la constitución de la Iglesia. Los intensos, apasionados debates en que se enmarca la intervención de don Alfonso concluyeron con la ruptura definitiva entre el papa y el concilio. Tal vez el momento de mayor confrontación entre ambas instancias de la Iglesia explica la naturaleza de los argumentos, tensado al máximo para hacer compatibles las legitimidades papal y conciliar, respectivamente.

Casualidad oportuna es que el uso de los loci aristotélicos en las dos obras aquí comentadas de Alfonso de Cartagena, ambas compuestas en Basilea, sirvan para refutar o corregir auctoritates jurídicas, tanto del Derecho Canónico como del Civil. La obra del Estagirita, erigida sobre la razón natural, se revelaba como la piedra de toque que permitía evaluar la calidad e idoneidad doctrinal de la ciencia jurídica. El erudito jurista se rendía a la evidencia del rigor científico de la doctrina ética y política de Aristóteles para cuestionar nada menos que una decretal y una ley del Digesto. En la jerarquía de auctoritates, Aristóteles ocupaba la posición más eminente.

Recibido: $16 / 04 / 2018$

Aceptado: 16/07/2018

${ }^{75}$ Domenicus Mansi, Sacrorum conciliorum nova et amplissima collectio, t. XXIX, Venecia, Apud Antonium Zatta, 1788, col. 178. Ofrece un detenido examen crítico de la recepción basiliense del decreto Haec sancta Johannes Helmrath, Das Basler Konzil, 1431-1449. Forschungsstand und Probleme, Colonia-Viena, Böhlau Verlag, 1987, pp. 460-477.

${ }^{76}$ Aspecto, junto con la importancia del elemento colegiado, destacado por Antony Black, Council and Commune, pp. 32-38. 


\title{
$\cos$
}

\section{Sobre el aristotelismo de Alfonso de Cartagena. EN EL DEBATE JURÍDICO Y ECLESIOLÓGICO}

\begin{abstract}
RESUMEN: El aristotelismo es la veta más representativa del pensamiento de Alfonso de Cartagena. En torno a su lectura de la Ética Nicomáquea se desarrollan sus dos primeras obras originales, el Memoriale virtutum (1425) y las Declamationes (1430), libelo contra la nueva traducción de Leonardo Bruni, que dio a conocer a raíz de su participación en el concilio de Basilea. Cartagena se revela como un aristotélico escolástico y con fuerte impronta tomista. Durante su misión diplomática en el concilio de Basilea compuso dos obras polémicas en las que el uso de Aristóteles fue determinante: el Tractatus super repetitione Ludovici de Roma (c. 1436-1437), inédito, y una oratio contra la facción conciliarista más radical (1439), de la que solo quedan las noticias de los historiadores del concilio (Pío II y Juan de Segovia). Ambas obras constituyen un testimonio sumamente revelador de los usos de Aristóteles en un momento crucial del debate eclesiológico sobre la naturaleza del poder papal.
\end{abstract}

Palabras Clave: Aristotelismo renacentista. Alfonso de Cartagena. Concilio de Basilea. Humanismo castellano.

\section{On the subject of Alfonso de Cartagena's Aristotelianism. \\ IN THE LEGAL AND ECCLESIOLOGICAL DEBATE}

AbSTRACT: Aristotelianism is the most characteristic facet of the Alfonso de Cartagena's thought. His two first original works address Aristotle's Ethic: Memoriale virtutum (1425) and Declamationes (1430). He reveals himself as a scholastic and strong thomistic aristotelian. Cartagena judged that his mission as ambassador in Basel would be a good occasion to make his Declamationes public among humanists, specially his defense of the antiqua translatio from the scholastic point of view facing the Bruni's attacks. During this mission he composed two works in which the use of Aristotle was decisive: the Tractatus super repetitione Ludovici de Roma (c. 1436-1437) and an oratio against the most radical conciliar party (1439). The first one is unpublished. The second one is only known by the abstracts of two historians of the council of Basel, Pius II and Juan de Segovia. These works are a very interesting testimony of the uses of Aristotle in a crucial time of the ecclesiologic discussion about the nature of the papal power.

Keywords: Renaissance Aristotelism. Alfonso de Cartagena. Council of Basel. Humanism. 